
\title{
$\begin{array}{ll}\text { Research Square } & \begin{array}{l}\text { Preprints are preliminary reports that have not undergone peer review. } \\ \text { They should not be considered conclusive, used to inform clinical practice, } \\ \text { or referenced by the media as validated information. }\end{array}\end{array}$
}

\section{ATR Signalling mediates the prosurvival function of phospho-NPM against PIDDosome mediated cell death}

\section{Disha Hiregange}

Tata Institute of Fundamental Research

Hemanth Naick

Indian Institute of Science Education and Research, Tirupati

Basuthkar J Rao ( $\sim$ bjrao@iisertirupati.ac.in )

Indian Institute of Science Education and Research, Tirupati

\section{Research article}

Keywords: ATR kinase, PIDDosome. Nucleophosmin, Chk1 kinase. Apoptosis

Posted Date: July 3rd, 2019

DOI: https://doi.org/10.21203/rs.2.10953/v1

License: @ (i) This work is licensed under a Creative Commons Attribution 4.0 International License. Read Full License

Version of Record: A version of this preprint was published at Cellular Signalling on July 1st, 2020. See the published version at https://doi.org/10.1016/j.cellsig.2020.109602. 


\section{Abstract}

Background: ATR kinase is studied largely in the context of externally imposed genotoxic stress, even though its endogenous basal level plays important homeostatic cellular functions. Results: We show that pNPM triggers the dissociation of NPM from P1DD thus preventing the cell from undergoing caspase 2 mediated cell death via PIDDosome, thereby acting as an endogenous negative regulator keeping the PIDDosome activation under check. pChk1 interacts with NPM before phosphorylating it, which is abrogated following ATR kinase inhibition, dropping nucleoplasmic/chromatin pNPM level, thereby inducing PIDD. Expectedly, phosphodead mutants of Chk1 and NPM are not viable as the pNPM regulatory axis is abrogated, whereas the phosphomimic mutants of Chk1 and NPM render cells refractory to ATR/pChk1 kinase inhibition induced cell death. Interestingly, cells expressing phosphomimic mutant of Chk1(S345E) withstand ATRi, but not Chk1i mediated PIDDosome activation implying that the Chk1 kinase plays a direct role in pNPM homeostasis, even in the absence of replication stress. Conclusion: In the current study, we uncover the non-canonical role of ATR kinase in the control of PIDDosome activation, and show that under normal cellular conditions involving no replication stress, ATR kinase controls the phosphorylation of NPM via pChk1 and the two phosphatases regulating pNPM, namely, PPM1D and PP1ß.

\section{Background}

ATR (Ataxia Telangiectasia and Rad3-related) is a protein belonging to the phosphatidylinositol 3-kinase-related kinase (PIKKs) family, which phosphorylates the serine or threonine residues that are followed by glutamine (SQ/TQ). The known physiological function of ATR mainly focuses on its role as a DNA damage response kinase, largely in the context of externally imposed genotoxic or replication stress conditions $(1,2)$. ATR kinase is the primary mediator of replication stress response which activates the checkpoint protein Chk1 by phosphorylating it at S345 and S317 leading to cell cycle arrest (3-5). In a proliferating cell, ATR kinase regulates the timing of replication origin firing and elongation of the fork $(6,7)$. ATR has been shown to regulate WRN helicase and BLM helicase in a positive manner for controlling the origin function and protection of the stalled fork $(8,9)$. However, the endogenous role of ATR kinase in the absence of imposed genotoxic stress is not clearly defined, even though the kinase has been shown to play a crucial role in the functional maintenance of organelles such as mitochondria (10), centrosomes (11), nuclear envelope and nucleoli $(12,13)$.

In this study, using a specific chemical inhibitor that inhibits the ATR kinase enzymatic activity, we probe the role of endogenous basal ATR kinase in cell protection functions. It has been shown earlier that the structural alteration of nuclear envelope leads to non-canonical activation of ATR but the significance of the same has not been clear (13). Recent studies have also revealed that the alteration of nucleolar homeostasis results in the activation and relocalisation changes of ATR kinase $(12,13)$. The loss of ATR kinase in ES cells leads to an early embryonic lethality in mice $(14,15)$ suggesting that the ATR kinase performs significant prosurvival functions in the cell even in the absence of externally imposed genotoxic stress.

Interestingly, inhibition of an important ATR downstream target, Chk1 kinase, has been ascribed to activate PIDDosome signalling resulting in caspase 2 mediated cell death $(16,17)$. In addition, the distribution of Nucleophosmin (NPM), a mediator of PIDDosome function (18). on chromatin, is shown to be modulated by Chk1 kinase during DNA damage (19). NPM, a nucleolar phosphoprotein also called as B23/NO38/Numatrin, is known to be involved in multiple cellular functions such as ribosome biogenesis, centrosome duplication, protein chaperoning, histone octamer assembly, cell proliferation, and the regulation of tumour suppressor proteins such as p53/TP53 and ARF (20-24). It is relevant to note here that $n p m 1$ knockdown not only leads to embryonic lethality in mice (25) but also to distorted nuclear and nucleolar structure (22), a condition that was shown earlier to lead to ATR activation. However, intriguingly enough, NPM has also been shown to interact with PIDD of PIDDosome complex and shown to be essential for caspase 2 mediated cell death via PIDDosome signalling (18). 
Cellular pNPM level is finely tuned by two oppositely acting phosphatases, namely PPM1D and PP1 $\beta$. PPM1D phosphatase upregulation results into increased level of pNPM and hence increased nucleolar number, a hallmark of cancer cell. A signaling pathway involving PPM1D-CDC25C-CDK1-PLK1 axis leads to the upregulation of pNPM levels in the cell (26). PP1 $\beta$ is a protein phosphatase involved in regulation of cellular processes like cell cycle progression, glycogen metabolism and abundantly found in liver and muscle cells. Studies have also shown that PP1 $\beta$ dephosphorylates NPM at T199 and facilitates interaction of NPM and retinoblastoma tumour suppressor protein in response to DNA damage thereby facilitates E2F1 responsive gene transcription including that of DNA repair and cell death causing genes (27).In terms of kinase regulation of PIDDosome action, it has been documented that following DNA damage, ATM kinase phosphorylates PIDD at T788 and activates PIDDosome signalling resulting into caspase 2 mediated cell death (17). In stark contrast, Chk1 kinase has been shown to act as a negative regulator of PIDDosome signalling but the mechanism of the same has remained elusive $(17,28)$.

The PIDDosome complex is assembled when PIDD (p53 induced death domain protein) binds RAIDD (Receptor interacting protein [RIP]-associated ICH-1/CED-3 homologous protein with a death domain) and acts as an activation platform for caspase 2(18,29). The complex consists of two stacked rings with a staggered hexagonal pattern, which includes five PIDD DDs and seven RAIDD DDs and serve as an activation platform for recruiting seven caspase 2 molecules and has a predicted molecular weight of $696.8 \mathrm{kDa}(18,29-37)$. Given the architecture of the PIDDosome, its regulation of assembly/activation itself is complex, wherein caspase 2 activation is strictly linked to PIDDosome assembly. Moreover, caspase 2 is an evolutionarily conserved minor initiator caspase whose activation is triggered by the proximity induced dimerization on an activation platform such as the PIDDosome $(30,31,35)$. Caspase 2 is also a tumour suppressor (38) which is activated in DNA damage condition in both p53 dependent as well as p53 independent manner $(16,17,28,39-41)$. No integrated mechanism has been proposed yet that connects all the inputs leading to the activation of caspase 2 , perhaps due to its perceived status of being a minor caspase.

However all these disparate findings, put together, raised several interesting mechanistic queries about PIDDosome regulation in the context of dynamic functions of NPM vis-à-vis ATR and Chk1 kinase activity regulation in the normal unstressed cells; namely, NPM roles in the nucleolus versus chromatin, its crosstalk with Chk1 in the context of PIDDosome mediated cell death, and more importantly the role of ATR that is activated during distortion of nuclear and nucleolar structures in $n p m 1$ knockouts. In order to address such mechanistic questions related to the PIDDosome function, in this study, we set out to studying the cellular changes associated with ATR inhibited cells (ATRi) and probed the relationship between ATR, Chk1, and PIDDosome function specifically in the context of NPM. We surmised that such an attempt will provide insights on lesser known and non-canonical types of pro-survival ATR kinase functions wherein the cellular DNA damage levels are maintained low.

In the current study, we provide the cellular and biochemical evidence that the ATR kinase has a cell protective role during normal cellular conditions, wherein no endogenous DNA damages are induced and the protein actively prevents the cell from undergoing caspase 2 mediated cell death. Our results show that under such cellular conditions, ATR kinase regulates the phosphorylation of NPM via pChk1 and balancing the two oppositely acting phosphatases, namely, PPM1D and PP1 $\beta$, on pNPM, thereby leading to the dissociation of NPM from P1DD, thus preventing the cell from tipping into caspase 2 mediated cell death since NPM is essential for PIDDosome mediated cell death. We also uncovered that in the absence of ATR kinase activity in normal cells (ATRi condition), the phosphorylation status of NPM is severely reduced, which in turn promotes the interaction of NPM with PIDD, thus activating the PIDDosome signalling resulting in caspase 2 mediated cell death. We propose that the ATR kinase maintains the phosphorylated form of NPM via its stable association with Chk1 (that the interaction can be scored by a classical immunoprecipitation assay) and thereby protects the cell from undergoing caspase 2 mediated cell death in its default state. We corroborate the same finding by showing that the phosphomimic mutant of NPM renders the cells refractory to ATRi mediated cell death. However the phosphomimic mutant of pChk1 renders the cell refractory to ATRi, but the same fails in Chk1i conditions, unveiling the direct role of Chk1

Page 3/21 
rather than ATRi kinase in the phosphorylation of NPM. We propose a model that captures these effects into a mechanistic scheme reflecting the role of ATR kinase in normal cells where the PIDDosome mediated cell death programme is kept under check. This result stands in strong contrast with the activated ATR kinase functions that are modulated by proteins such as Top-BP1 and ATRIP1 during replication stress and DDR conditions $(42,43)$.

\section{Methods}

\section{Cell culture and Drug treatments:}

Normal human dermal fibroblasts (NHDFs) and human embryonic kidney cells (HEK293) (Sigma-Aldrich) were grown in Dulbeco's modified Eagle's Medium (DMEM, 1g/l glucose, 200 mM Glutamine) (HiMedia) suplemented with 15\% fetal bovine serum (FBS) (HiMedia) and 10\% FBS respectively. The cells were maintained at $37^{\circ} \mathrm{C}$ in $5 \% \mathrm{CO}_{2}$. For indicated periods, ATR kinase was specifically inhibited using inhibitor VE-821 (Calbiochem), ATM kinase was inhibited using KU55933 (Calbiochem), DNAPKcs was inhibited using LY293646 (Calbiochem), Chk1 kinase was inhibited using CAS 1177150-89-8 (Calbiochem). PPM1D was inhibited using GSK2830371. All the inhibitors were reconstituted in DMSO and added to complete culture media at a final concentration of $15 \mu \mathrm{M}$. Latrunculin B was used as cytoskeletal disrupter. For inducing double strand break (DSB) formation, cells were treated for 4 hours with $25 \mu \mathrm{M}$ of cisplatin (Calbiochem) reconstituted in DMSO.

\section{Comet Assay:}

Cells were trypsinized and were centrifuged at $1200 \mathrm{rpm}$ for 5 minutes. Cell pellet was washed with 1X PBS thrice. Cell were suspended in $200 \mu \mathrm{l}$ 1X PBS and mixed with low melting agarose at a dilution of 1:10. The mixture was placed on prewarmed Trevigen comet slides and were kept at room temperature for 30 minutes to let the cells settle down. Lysis solution ( $\mathrm{NaCl}, \mathrm{Na}_{2} \mathrm{EDTA}$, Tris $\left.\mathrm{HCl}, \mathrm{NaOH}\right)$ was added on to the slides and was incubated at room temperature for 60 minutes (or overnight at $4^{\circ} \mathrm{C}$ ). For alkaline comet assay, the lysis buffer was removed and chilled alkaline unwinding solution was added and incubated for 30 minutes. Alkaline unwinding solution was removed and the slides were placed in electrophoresis tray and alkaline electrophoresis buffer was added and a voltage of $21 \mathrm{~V}(300 \mathrm{~mA})$ was applied. For neutral comet assay slides were placed on an electrophoresis tray and neutral electrophoresis buffer added and a voltage of $21 \mathrm{~V}$ (300 mA) was applied. Electrophoresis buffer was drained and slides were washed with distilled water thrice for 5 minutes. Slides were immersed in $70 \%$ ethanol for fixation. Slides were dried at $37^{\circ} \mathrm{C}$ (to facilitate the cells to be in a single plane). The comets were stained with SYBR green at room temperature for 30 minutes and were dried at $37^{\circ} \mathrm{C}$ and were observed using a ZIESS 510 Confocal microscope at 40X magnification.

\section{Immunofluorescence (IF) assay:}

NHDF and HEK293 cells were grown on $12 \mathrm{~mm}$ round glass coverslips (Blue star) till they attained $50-60 \%$ confluency. After appropriate inhibitor treatment (mentioned in 2.1), coverslips were collected, washed thrice in 1X PBS and were incubated in $4 \%$ paraformaldehyde for fixation. This was followed by incubating the cells in $1 \%$ Triton X-100 in PBS, for 20 minutes at room temperature. Blocking of fixed cells was performed using 1\% BSA in PBS for 1 hour at room temperature and this was followed by incubation in primary antibody diluted in 1\% BSA in PBS for 1hour at room temperature. Primary antibodies used were: mouse anti-PIDD (1:300, Merck), mouse anti Caspase 2 (1:100, Santa Cruz Biotechnology), rabbit anti p-NPM (Thr199) (1:500, Cell Signaling Technologies), mouse anti-RAIDD (1:500, Abcam) and mouse anti-pATM (1:50, Santa Cruz Biotechnology), rabbit anti-p53 (1:500, Cell Signaling Technologies), rabbit anti-caspase 3 (1:100, Santa Cruz Biotechnology) mouse anti-NPM (1:500, Abcam), rabbit anti-Flag (1:1000, Sigma), Rabbit anti-PP1 $\beta(1: 200$, Merck). This was followed by washing the cells in PBS and further incubated with appropriate secondary antibodies at room temperature for $1 \mathrm{~h}$ : donkey anti-rabbit Alexa 488 or donkey anti- mouse Alexa 488 (Molecular probes, Invitrogen). This was followed by washing the cells in PBS and distilled water and mounting the coverslips on slides using Vectashield Antifade 
Mounting medium containing DAPI (Vector Laboratories) which counterstains the nucleus. Cells were observed under ZIESS 510 microcope at 40X,60X and 100X magnification and subsequent analysis was performed using ImageJ software.

\section{Cellular Fractionation and western blotting:}

Cells were harvested and washed with cold 1X PBS. Lysis solution (10 mM Tris pH 7.4, $150 \mathrm{mM} \mathrm{NaCl}, 10 \mathrm{mM} \mathrm{KCl}, 1 \mathrm{mM}$ EDTA, $0.5 \%$ deoxycholic acid, $0.5 \%$ Tween $20,0.5 \%$ NP40, $0.1 \%$ SDS), protease and phosphatase inhibitors (Roche) were added to the pellet and incubated on ice for 30 minutes and centrifuged at $12000 \mathrm{rpm}$ for 30 minutes at $4^{\circ} \mathrm{C}$. Then, Laemmli sample buffer (50 mM Tris-HCl, pH 6.8, $100 \mathrm{mM}$ mercaptoethanol, 1\% sodium dodecyl sulphate [SDS], 10\% glycerol, $0.0025 \%$ bromophenol blue) was added and the samples were boiled for 10 minutes at $100^{\circ} \mathrm{C}(57)$. This was followed by resolving the samples in acrylamide gels (10\%, $12 \%$ gels) and blotting on to nitrocellulose membrane having pore size of 0.45 micron (Biorad). Transfer was followed by blocking with 5\% BSA in 1X $0.5 \%$ TBST and incubation with primary antibody against the protein of interest. Primary antibodies used were rabbit anti-pNPM (1:1000, Cell Signalling Technologies), rabbit anti-PIDD (1:1000, Biorad), mouse anti-Caspase 2 (1:200, Santa Cruz Biotechnology), mouse antiRAIDD (1:200, Santa Cruz Biotechnology), rabbit anti-pChk1 (Ser 345) (1:1000, Cell Signalling Technologies) mouse antip53 (1:200, Santa Cruz Biotechnology), rabbit anti-yH2AX (1:1000, Abcam), rabbit anti-pChk2 (1:1000, Abcam), mouse antiNPM (1:5000, Abcam). The blots were further incubated with appropriate secondary antibody (HRP-conjugated anti-rabbit and anti-mouse IgGs [1:5000] [Sigma]) at room temperature for 1hour and visualised using Clarity max western ECL substrate (Biorad).

\section{Immunoprecipitation:}

Cells were harvested and washed with cold 1X PBS. Lysis solution (20 mM Tris HCl, $150 \mathrm{mM} \mathrm{NaCl}, 1 \%$ IGPAL), protease and phosphatase inhibitor were added to the pellet and incubated on ice for 30 minutes and centrifuged at $12000 \mathrm{rpm}$ for 30 minutes at $4^{\circ} \mathrm{C}$. Then, the lysate was precleared with appropriate beads to avoid non-specific binding and incubated with primary antibody for 16 hours at $4^{\circ} \mathrm{C}$. The protein was then pulled down by incubating the lysate with appropriate beads for 4 hours at $4^{\circ} \mathrm{C}$. This was followed by centrifugation at $2300 \mathrm{rpm}$ for 3 minutes. The pellet was washed with lysis buffer thrice. Laemmli sample buffer was added and the samples were boiled for 10 minutes at $100^{\circ} \mathrm{C}$. This was followed by western blotting.

\section{Apoptosis Assays:}

Annexin V FITC PI assay was performed using Annexin V FITC early apoptosis detection kit (Cell Signalling Technology) according to manufacturer's instructions. Cells were observed under a ZIESS 510 confocal microscope at 20X and 63X magnification.

Trypan blue dye exclusion test was performed as follows: Cell suspension ( $50 \mu \mathrm{l})$ and $0.4 \%$ trypan blue dye $(50 \mu \mathrm{l})$ were mixed by pipetting up and down in a vial. (Note: This mixture was incubated for less than 3 minutes as otherwise inaccurate results could be obtained due to cell death caused by the dye itself.) The mixture was placed on the coverslip and the number of blue cells and unstained cells were counted using a light microscope. Blue cells were the dead cells. The percentage of dead cells was calculated by dividing the number of dead cells by the total number of cells and multiplying by 100 .

\section{Transfection and Cloning:}


Wild type GFP tagged NPM cDNA plasmid (Cat\# 17578) (58), and flag-tagged CHK1 cDNA plasmid (Cat\# 86875) (59) were obtained from Addgene (Additional Table 1). Site-directed point mutations were performed to generate phosphodead mutations T199A, S345A and phosphomimetic mutations T199D, S345E for NPM and CHK1 respectively by using QuickChangell site-directed mutagenesis kit (Stratagene) according to the manufacturer's instructions. The mutagenized plasmids were isolated using GeneJET Plasmid Miniprep Kit (ThermoScientific) according to manufactures instructions. The point mutations were confirmed using Sanger's sequencing (Macrogen, South Korea) and compared with reference sequence in GenBank. Primers used in mutagenesis reactions are listed in Additional Table 2.

\section{Caspase 2 Assay:}

HEK293 cells were treated with ATR kinase inhibitor and Chk1 kinase inhibitor for $5 \mathrm{~h}$. Cells were harvested and lysed using RIPA lysis buffer. In a 96 well plate $100 \mu$ of reaction buffer with $200 \mu \mathrm{g}$ of protein were mixed. Substrate VDVAD-p-NA was added to the mixture and incubated at 37 degree Celsius for $3 \mathrm{~h}$. Then absorbance was measured at $405 \mathrm{~nm}$.

\section{Colocalization Coefficient Measurements:}

Localization of PIDDosome proteins in the nucleus was detected and quantified using the JACoP plugin in Image J. Boundaries of individual cells were marked at the nuclei. Fifty cells from each experiment and a total of 150 cells from three different experiments were used for analysis. Threshold for images was set manually. Pearson correlation coefficient (PCC) and Mander's overlap coefficient (MOC) for PIDD overlapping with RAIDD and cleaved caspase 2 were calculated.

\section{Results}

\section{ATR kinase inhibition leads to cell death in unstressed normal cells}

It has been reported that loss of both the alleles of ATR gene leads to an early embryonic lethality but the underlying regulation remains unclear (14). To understand the role of ATR kinase activity in cell survival, we inhibited cellular ATR kinase activity using a specific chemical inhibitor VE-821 in NHDFs and HEK293 cells followed by annexin V FITC PI assay (Fig 1a-b) and trypan blue dye exclusion test (Fig 1b). These assays revealed that prolonged ATR kinase inhibition (ATRi) causes cell death, which was specific to ATRi but not to either ATM kinase inhibition (ATMi) or DNAPKc inhibition (DNAPKci). Chk1 kinase inhibition by a specific chemical inhibitor also resulted in cell death. Latrunculin B is a chemical inhibitor that blocks actin polymerisation whose prolonged state of inhibition also led to cell death, used as positive control (Fig 1a-b). Quantitative analyses showed that while ATRi, Chk1i and LatB samples exhibited hardly any cell survival (approximately $5-10 \%$ of cells), ATMi and DNAPKci led to the survival of $>80 \%$ cells in the populational assay (Fig $1 \mathrm{~b}$ ). In order to assess whether the cell death phenotype was associated with genome damage, we performed the comet assay.

\section{Prolonged ATR Kinase inhibition does not lead to genotoxic stress}

The comet assay was performed for double and single stranded breaks on ATRi samples from different time points of the inhibition regime. Surprisingly, ATRi condition did not exhibit any detectable comet tail formation, and neither double nor single stranded breaks were evident (Additional file 1). Hydroxyurea (2mM) treatment, a classical replication stressor, was used as a positive control that revealed strand breaks. In the same experiment, ATMi, DNAPKci and Chk1i also revealed no DNA strand breaks (Additional file 1). In the entire time course of inhibition, none of the kinase inhibitions led to any discernible DNA strand breaks (Additional file 1 data are shown only for alkaline comet assay). However, in these conditions where the strand breaks were not evident, only ATRi and Chk1i treatments led to cell death phenotype whereas ATMi and DNAPKci treatments yielded no cell death as evidenced by the robust cell survival in these conditions (Fig 1a-b). We were curious whether ATRi conditions evoked any ATM kinase activation signal: we scored pChk2 and $\mathrm{YH} 2 \mathrm{AX}$ signals as bonafide targets of active ATM kinase. As a direct readout of ATM activation, we also assayed for pATM staining during ATRi time course regime. Cisplatin $(25 \mu \mathrm{M})$ treatment was used as a positive control. Western blotting for pChk2, $\mathrm{YH} 2 \mathrm{AX}$ 
(Fig 1c) and immunofluorescence for pATM, pChk2, $\mathrm{yH} 2 \mathrm{AX}$ (Fig 2a-d) revealed that there was no activation of ATM kinase during the state of prolonged ATR kinase inhibition. Interestingly, in the same time-course, we observed transient increase of p53 protein by both western blotting as well as immunofluorescence assays wherein p53 protein reached its maximum by $2 \mathrm{~h}$ of ATRi followed by almost complete depletion of the same by the next $1 \mathrm{hr}$ which stayed so during $5 \mathrm{~h}$ ATRi treatment (Fig 1c, 2a). In the prolonged ATRi (5 hours) condition, where the cell death phenotype reached maximum (see the time-course result in the next experiment), p53 level had dipped to the basal value. To rule out the possibility of off target effects of ATRi and Chk1i, we probed for ATM kinase activity in the presence of ATRi and Chk1i under DNA damage inducing conditions (Cisplatin treated). Immunofluorescence for pChk2, yH2AX revealed that ATRi and Chk1i conditions did not lead to any measurable inhibition of ATM kinase function: both pChk2, $\mathrm{YH} 2 \mathrm{AX}$ markers were active during ATRi and Chk1i conditions, specifically during DNA damage induction (Fig 2e-f).

\section{Activation of PIDDosome signalling following ATR kinase inhibition}

Chk1 inhibition activates PIDDosome signalling but the mechanism remains unclear $(17,28)$. PIDDosome signalling is therefore referred to as "Chk1 inhibited death response" in the cells $(16,41)$. Chk1 undergoes ATR dependent phosphorylation at S345 (3). To test whether PIDDosome signalling is activated upon ATR kinase inhibition and the resultant cell death is indeed caspase 2 dependent, we performed IF assay for PIDDosome components in NHDFs. There are five known isoforms of PIDD (44-46), our study focuses on PIDD isoform 4 which lacks the LRR domain (47). It is known that PIDD4 is activated in a p53 dependent manner and promotes apoptosis in the cytoplasm (47). Caspase 2 assay revealed increased activity of caspase 2 in ATRi and Chk1i condition (Fig 3b). Caspase 3 cleavage and activation was not observed in both ATRi and Chk1i conditions (Additional file 3). Western blotting and IF assays revealed that PIDDosome signalling was indeed activated leading to the cleavage of caspase 2 during ATR and Chk1 kinase inhibition (Fig 3a-e) even under the conditions in which the p53 protein level had fallen to basal values (Fig 1c, 2a). Current models suggest that the PIDDosome complex is activated leading to caspase 2 cleavage in the nucleolar compartment during DNA damage and a similar PIDDosome response recurs in the cytoplasmic compartment during the conditions of cytoskeletal poisoning/disruption $(18,46,48,49)$. In addition, IF analyses of nucleolar markers such as nucleolin, fibrillarin and nucleophosmin revealed that nucleolar structure was distorted during the prolonged inhibition of ATR kinase activity in the cells (Additional file 2a, Fig 3c, 4c) whose effect was specific to ATR and Chk1 rather than DDR apical kinases (ATM and DNAPKc) inhibition (Additional file 2a). In order to probe the time-course of PIDDosome formation in these conditions, we scored for PIDDosome complex as a function of ATRi time-course which revealed that PIDD was induced and started accumulating by 1-2 hours of ATR kinase inhibition (Fig 3e, $3 \mathrm{~g}$ ) by when p53 protein level had reached maximum in the cells (Fig 1c, 2a). However, interestingly, the PIDD level increased even further during the time-course beyond the first 2 hours (Fig 3e-h) when p53 level decreased to the basal values (Fig 1c, 2a). Immunofluorescence assay also revealed the co-localization of PIDD/caspase 2 and PIDD/RAIDD; the coefficient of co-localisation for both pairs increased reaching the maximum by 5 hours of ATRi (Fig 3f-h).

\section{ATR kinase mediates the phosphorylation of NPM via Chk1 by regulating NPM-Chk1 stable interaction}

NPM has been shown to be essential for activation of PIDDosome signalling and Chk1 acts as the negative regulator of the same(18). NPM is mutated in about one third of adult Acute Myeloid Leukaemia (AML) patients (50) and (besides several other roles) has also been critically linked to cellular apoptosis function whose mechanistic basis is still unclear (51-53). Interestingly, while NPM is largely nucleolar in localization, pNPM is present both in the nucleoplasm/chromatin and nucleolus of the cell (Fig 4a-b). On ATR and Chk1 kinase inhibition, the phosphorylation of NPM at T199 is lost (Fig 4c, $4 \mathrm{~g})$. Chk1 interacts with NPM during DNA damage condition as an essential step for promoting NPM recruitment to the chromatin (19). Immunoprecipitation of pChk1(S345) revealed that Chk1 stably interacts with both NPM and pNPM in normal cellular conditions (Fig 4f). However, during ATR kinase inhibition time-course, available pChk1 shows a near complete loss of its interaction with NPM by 5 hours ATRi (Fig 4f-g). We note that even though NPM levels remain largely unaffected during both ATRi and Chk1i conditions, pNPM levels plummet (Fig 4g). We surmise that the gradual fall in the 
interaction between pChk1 and NPM during ATRi time course finally results in complete loss of pNPM after 3 hours of ATRi (Fig 4f). Interestingly, we observe an intermediate time-point (4h ATRi in Fig 4f) in this regime at which pChk1 interaction with NPM is detectable, but pNPM level fell to low level that it is hard to detect (see Discussion). We thus conclude that PIDDosome activation is associated with a significant drop in pNPM levels in ATRi cells (Additional file 2b and Fig 4c, 4f, $4 \mathrm{~g})$.

\section{Phosphorylation of NPM and Chk1 render the cells refractory to ATRi mediated cell death.}

To test whether the phosphorylation of NPM (T199) and Chk1 (S345) was essential for preventing the cells from caspase 2 mediated cell death, we made phosphodead and phosphomimic constructs of NPM (T199) and Chk1 (S345) and transfected them into HEK293 cells. Trypan blue dye exclusion test showed that cells overexpressing phosphodead mutants of NPM and Chk1 i.e., NPM (T199A) and Chk1 (S345A) were generally not viable even under normal conditions implying that these phospho-proteins are essential for normal cellular homeostasis (Fig 5a). In contrast, cells overexpressing phosphomimic mutants of NPM(T199D) and Chk1(S345E) did not show cell death even under the conditions of ATR kinase inhibition in the cells (Fig 5a). Surprisingly however, inhibition of Chk1 kinase activity in phosphomimic mutant cells of Chk1(S345E) resulted in cell death, but didn't have any effect on NPM(T199D) mutant cells (Fig 5a). This result implied that pChk1 kinase activity was essential for the cell protective function of pNPM. In order to test whether PNPM is directly regulated by ATR or Chk1 or both, we analysed the sensitivity of Chk1 inhibitor effect on Chk1(S345E) expressing cells and probed for pNPM (Fig 5b). Cell death assay results had already indicated that these mutant cells were specifically sensitive to Chk1i rather than ATRi conditions (Fig 5a). As expected, pNPM scoring showed that Chk1(S345E) expressing cells failed to reveal pNPM specifically in Chk1i and not in ATRi condition (Fig 5b), thereby implying that pNPM is directly under the Chk1 rather than ATR kinase control. In order to probe the mechanism further, we stained for PIDD and cleaved caspase 2 markers in these mutant cells. Expectedly, the cells that were refractory to cell death even under prolonged ATRi conditions showed avoidance to PIDD and caspase-2 activation specifically in NPM(T199D) or Chk1(S345E) expressing cells (Fig 5c-h). In the same experiment, control cells that were not transfected with NPM(T199D) or Chk1(S345E) reproduced the ATRi effect exhibiting PIDDosome and caspase 2 activation (Fig 5c-h). Quantitation revealed that phosphomimick mutants (T199D \& S345E) exhibited robust avoidance of PIDDosome and caspase 2 activation (Fig $5 \mathrm{~g}$-h). This experiment clearly demonstrated that ATR kinase was upstream to both pNPM and pChk1 modulators in the system where pNPM acts as a negative regulator of PIDDosome and caspase 2 activation during ATRi conditions. Inhibition of Chk1 kinase activity prevents pNPM formation even though cells possess activated form of Chk1 mimic [Chk1(S345E)] which is NPM interaction competent where the stable interaction of pChk1 with NPM constitutes the first step of the mechanism whereas its phosphorylation by pChk1 constitutes the second discernible step. This model, for the first time, opens up an interesting possibility of pChk1 kinase activity modulation impacting PIDDosome function following its interaction with NPM protein in the nucleolus (see Discussion).

\section{Phosphatases in regulation of PIDDosome signalling}

Phosphorylation of NPM is regulated by PPM1D phosphatase(26). PPM1D overexpression upregulates the phosphorylation of NPM at S4 and T199 resulting into increased nucleolar number, a hallmark of cancer cell(26). PP1 is known to dephosphorylate pNPM(T199) and facilitate activation of E2F1 responsive genes in response to DNA damage(27). However, no single phosphatase has been implicated in regulation of PIDDosome signalling. In our previous study, we showed that ATR kinase activity is essential for spatial localisation and stabilisation of PPM1D in endogenous conditions of normal cells.

In order to understand the phosphatase regulation of PIDDosome signalling, we probed the involvement of PPM1D and PP1 $\beta$, the two phosphatases known to inversely regulate pNPM status in the cells. Expectedly, inhibition of PPM1D phosphatase led to cell death and time-course study of the same showed a measurable drop in pNPM level associated with increased PIDD induction, thus reinforcing the interpretation that inhibition of PPM1D phosphatase results into

Page $8 / 21$ 
caspase 2 mediated cell death (Fig 6a-b). Furthermore, we probed the changes of PP1 $\beta$ phosphatase by immunofluorescence. Immunostaining for PP1 $\beta$ phosphatase as a function of ATR inhibition revealed interesting changes: Firstly, PP1 $\beta$ staining encompassed both nuclear as well as cytoplasmic segments in ATR normal state, but changed exclusively to nucleus in ATR inhibited cells (Fig 6c-d). But interestingly, the PP1 $\beta$ nuclear intensity also dropped as a function of ATR inhibition time-course by 5 h ATRi (Fig 6c-d).

All these results put together suggest that ATR kinase actively maintains pNPM levels in the cells via Chk1 axis. We integrate these results into a model where we suggest that ATR kinase maintains the cellular pool of pChk1 and regulates the spatial localisation of PPM1D and PP1 $\beta$ phosphatase, which in turn leads to the build-up of sufficient level of pNPM in normal cells such that the normal cells are actively protected from NPM mediated activation of PIDDosome and caspase-2 functions, thereby preventing the cells from "tipping" into cell death. Either ATR or Chk1 inhibition leads to the imbalance of such finely tuned cellular homeostatic control via the loss of pNPM in the cell following which NPM protein triggers the activation of PIDDosome signalling, thus leading to caspase 2 mediated cell death (Fig 7).

\section{Discussion}

ATR is a major DNA damage response (DDR) kinase whose mechanistic function has been probed largely in the context of externally imposed genotoxic stress and replication stress in mammalian cells $(1,2)$. Therefore most of the mechanistic ATR biology known to date relates to its activated form of the protein that is tightly regulated by TOPBP1 and ATRIP type of modulators $(42,43,54)$. Hardly any mechanistic studies are reported that detail the molecular action of ATR kinase which is basally active in normal cells, even though several studies had underscored that the endogenous level of the protein is critically involved in the maintenance of the nuclear envelope (13), nucleolus (12), centrosome (11), and mitochondrial (10) structure and functions.

Motivated by these indications that the endogenous ATR kinase in its basal state of activation is likely to be crucially important in cellular organellar homeostasis control, we undertook the current study where we systematically tuned down the ATR kinase activity in normal human cells and analysed the cellular consequences, molecularly and show a novel noncanonical cell protective role of ATR kinase against the PIDDosome mediated, caspase 2 dependent death response. In surprising contrast, previous findings had uncovered that ATM, another prominent apical kinase involved in DDR, acted as a positive regulator of caspase 2 mediated cell death where the activation of ATM kinase results in phosphorylation of PIDD at T788, thereby activating cell death (17). Here we show that the endogenous ATR kinase activity is mandatory for preventing the normal cells from "tipping" into death-regime. We elaborate the molecular basis of the same via the classical Chk1 kinase axis.

Caspase 2, deemed to be a minor caspase in mammalian cells, is activated on a high molecular weight platform known as the PIDDosome $(30,31,35)$, which is assembled when PIDD binds RAIDD $(29)$. Both cytoplasmic and nucleolar compartments act as "homes" for the assembly of PIDDosome complexes (18,47-49). In the current study, we focus on PIDDosome assembly in the nucleoplasm/chromatin during the time-course of ATR kinase inhibition achieved using a specific pharmacological inhibitor.

The regulation of PIDDosome assembly is known to be rather complex: In response to genotoxic stress, Janus-faced PIDD seems to determine whether a cell survives or not, wherein if PIDD binds to pro-apoptotic adaptor protein RAIDD, the cell will die, but if it binds to the prosurvival modulator RIP1, the cell survives $(17,55)$. One of the recent findings places NPM, the nucleolar protein, as a crucial interactor of PIDD triggering PIDDosome assembly and therefore has been shown to be essential for caspase 2 mediated cell death(18).Caspase 2 mediated death was originally discovered in a screen as a "Chk1-suppressed" pathway that can be triggered in p53-deficient human tumour cells (28). Caspase 2 death pathway

Page $9 / 21$ 
linkage to PIDDosome signalling was uncovered when it was independently discovered that Chk1 kinase acts as a negative regulator of PIDDosome signalling whose details of regulation remained unclear $(16,17,28)$. The study by Sidi et al, also showed that Chk1 inhibitor treated tumour cells show hyper-activation of ATM, ATR and caspase 2 after gammairradiation followed by triggering of cell death response (28). All these tell-tale signs revealed a nexus between ATR-Chk1Caspase 2 leading to PIDDosome signalling during genotoxic stress conditions especially in the context of p53 deficient cells.

We took the cue from this background and probed whether the same axis has a role in PIDDosome homeostasis in normal cells that have not been subjected to any genotoxic stress. We followed a simple approach of tuning the ATR kinase activity down in normal cells and assessed the status of PIDDosome mediated caspase 2 activation mechanistically.

Chk1 gets activated by ATR dependent phosphorylation at S345 which is important for cell cycle arrest (3). Our results showed another facet of pChk1 function where it stably interacts with NPM and phosphorylates the same into pNPM and the interaction between the two proteins is lost upon prolonged ATR kinase inhibition. And the loss in this protein-protein interaction was not due to a trivial consequence of pChk1 depletion itself, as the same was detectable even during the ATRi time course (Fig 4f). Moreover NPM levels remain unabated during the entire time-course of ATRi (Fig 4d-e). It is plausible that dysregulation of entire nucleolar architecture during ATRi regime (current study) (Fig 3c, 4c, Additional file 2a) or its cognate phosphatase PPM1Di (56) leads to a large-scale imbalance in the nucleolar function thereby impacting pChk1 and NPM interaction. We discovered that one of the critical outcomes of such downregulation of pChk1-NPM interaction was the decrease in the level of pNPM. We also uncovered, for the first time, that PIDDosome activation was intimately associated with the decrease in pNPM level in the nucleoplasm/chromatin. Studying phosphomimic mutants of Chk1 and NPM that escape the caspase 2 mediated cell death following ATR kinase inhibition elucidated the novel epistatic mechanism of pChk1-pNPM mediated control of PIDDosome signalling by ATR kinase. We note that while NPM was predominantly located in the nucleolar compartment, pNPM was distinctly nucleoplasmic/chromatin-bound (Fig 4a). NPM being a positive regulator of PIDDosome complexes, then enjoins the latter to largely associate with the nucleolar compartment (18). However our PIDDosome staining revealed that they were largely either nucleoplasmic or chromatin localised, based on which we speculate that PNPM negatively regulates PIDDosome assembly in the

nucleoplasmic/chromatin compartment of the cell in its normal unstressed conditions. This ensues by the interruption of NPM interaction with PIDD and RAIDD components thereby attenuating the assembly of PIDDosome complex. It is possible that the NPM/pNPM ratio dictates PIDDosome versus histone chaperone functions of NPM protein, and the site of phosphorylation of NPM may play an important role of a switch between the two disparate processes.

Based on all these results and other published findings put together, we propose the following model: ATR kinase, rather than ATM or DNAPKc kinases, performs a crucial cell protective role under normal cellular conditions when genotoxic stress or DDR is not induced. Homeostatic balance between ATR and PPM1D phosphatase (56).regulates the nucleolar morphology/architecture and associated biochemical functions such that PIDDosome assembly and caspase 2 activation are kept under control to a basal level (Fig 6a-b). This is achieved by the maintenance of certain threshold level of active Chk1 (pChk1) which interacts with NPM and phosphorylates the same, thereby preventing the stochastic triggering of PIDDosome complexes. In addition, ATR kinase wards off the dephosphorylation of pNPM by PP1 $\beta$ by keeping the nuclear phosphatase level under check (Fig 6c-d). In summary, ATR kinase maintains a fine balance of marking the phospho mark on NPM via pChk1, maintains the same by stabilising PPM1D distribution and preventing the nuclear accumulation of dephosphorylating enzyme, PP1 $\beta$. Interestingly, ATR kinase seems to conversely regulate the localization of these two phosphatases: PPM1D is prevented from spilling over to the cytoplasm from nucleus, while conversely PP1 $\beta$ is prevented from entering into the nucleus, where eventually both mislocalised phosphatases are degraded in ATRi conditions [Fig 8 and Fig 9 in (56) \& Fig. 6a-d, current study]. Cumulatively, a fine balance between NPM and pNPM maintains the PIDDosome signalling in normal cells to the bare minimum, which is imbalanced during any cellular stress condition that leads to nucleolar disruption, resulting into ATR/PPM1D dysregulation. 
Finally, we conclude that the current study opens up interesting unresolved queries that can form an exciting sequel study, namely the following - How does the cellular stress transmit to nucleolar dysregulation such that ATR/PPM1D axis is impacted. Who are the molecular sensors in the nucleolar proteome? What are the other components in the nucleolar structures that act as "toggle switches", if any, between PIDDosome assembly (cell-death) and disassembly (cellprotection) regulation. Mapping NPM/pNPM ratios in the context of histone chaperone versus PIDDosome activity status control is another interesting open question. We believe that the current study serves as an interesting new "primer" for such detailed mechanism-centric studies in future.

\section{Conclusions}

In an attempt to understand the riddle of how ATR kinase plays a cell protective role in endogenous conditions, devoid of imposed genotoxic stress, we uncover a novel function for ATR-pChk1 kinase axis and show that by homeostatically maintaining pNPM/NPM ratio, actively prevents PIDDosome mediated caspase-2 dependent cell death. We show that phosphodead mutants of Chk1 and NPM are not viable as the pNPM regulatory axis is abrogated, whereas the phosphomimic mutants of Chk1 and NPM render the cells refractory to ATR/pChk1 kinase inhibition induced cell death. Moreover, cells expressing phosphomimic mutant of Chk1 (S345E) withstand ATRi, but not Chk1i mediated PIDDosome activation implying that the Chk1 kinase plays a direct role in pNPM homeostasis, even in the absence of replication stress. In the current study, we uncover the non-canonical role of ATR kinase in the control of PIDDosome activation, and show that under normal cellular conditions involving no replication stress, ATR kinase controls the phosphorylation of NPM via pChk1 and the two phosphatases regulating pNPM, namely, PPM1D and PP1 $\beta$.

\section{Declarations}

\section{Acknowledgements:}

We are also grateful to Mr. Soumajit Saha, Ms Komal Raina and Ms. Shreya Joshi for their inputs and support.

\section{Funding:}

This work was supported by the funding from TIFR (Grant No. 12P-0123) (Department of Atomic Energy, India), IISERTirupati (MHRD) to BJR and Sir JC Bose Award Fellowship (Department of Science and Technology, India) to BJR (Grant No. 10X-217).

\section{Availability of data and material:}

All data generated or analysed during this study are included in this published article and its supplementary information files.

\section{Ethics approval and consent to participate}

Not Applicable

\section{Consent for publication}

Not Applicable

\section{Authors' contributions}

BJR and DH designed the experiments. DH performed the experiments. HN did cloning and generated mutants. DH analysed the data. BJR and DH wrote the manuscript. All authors read and approved the final manuscript. 


\section{Competing Interest}

The authors declare that they have no competing interests with the contents of this article.

\section{References}

1. Cimprich KA, Cortez D. ATR: an essential regulator of genome integrity. Nat Rev Mol Cell Biol [Internet]. 2008;9(8):61627. Available from: http://www.nature.com/doifinder/10.1038/nrm2450

2. Saldivar JC, Cortez D, Cimprich KA. The essential kinase ATR: ensuring faithful duplication of a challenging genome. Nat Publ Gr [Internet]. 2017;18(10):622-36. Available from: http://dx.doi.org/10.1038/nrm.2017.67

3. Capasso H. Phosphorylation activates Chk1 and is required for checkpoint-mediated cell cycle arrest. J Cell Sci [Internet]. 2002;115(23):4555-64. Available from: http://jcs.biologists.org/cgi/doi/10.1242/jcs.00133

4. Fragkos M, Ganier O, Coulombe P, Méchali M. DNA replication origin activation in space and time. Nat Rev Mol Cell Biol [Internet]. 2015;16(6):360-74. Available from: http://www.nature.com/doifinder/10.1038/nrm4002

5. Ge XQ, Blow JJ. Chk1 inhibits replication factory activation but allows dormant origin firing in existing factories. J Cell Biol. 2010;191(7):1285-97.

6. Toledo LI, Altmeyer M, Rask MB, Lukas C, Larsen DH, Povlsen LK, et al. ATR prohibits replication catastrophe by preventing global exhaustion of RPA. Cell [Internet]. 2014;156(1-2):374. Available from:

http://dx.doi.org/10.1016/j.cell.2013.10.043

7. Petermann E, Caldecott KW. Evidence that the ATR/Chk1 pathway maintains normal replication fork progression during unperturbed S phase. Cell Cycle. 2006;5(19):2203-9.

8. Davies SL, North PS, Hickson ID. Role for BLM in replication-fork restart and suppression of origin firing after replicative stress. Nat Struct Mol Biol [Internet]. 2007;14(7):677-9. Available from:

http://www.nature.com/doifinder/10.1038/nsmb1267

9. Pichierri P, Rosselli F, Franchitto A. Werner's syndrome protein is phosphorylated in an ATR/ATM-dependent manner following replication arrest and DNA damage induced during the $S$ phase of the cell cycle. Oncogene.

2003;22(10):1491-500.

10. Pin I, Hilton BA, Li Z, Musich PR, Zhou XZ, Hilton BA, et al. ATR Plays a Direct Antiapoptotic Role at Mitochondria, which Is Regulated by Prolyl Isomerase Pin1. Mol Cell [Internet]. 2015;60(1):35-46. Available from: http://dx.doi.org/10.1016/j.molcel.2015.08.008

11. Zhang S, Hemmerich P, Grosse F. Centrosomal localization of DNA damage checkpoint proteins. J Cell Biochem. 2007;101(2):451-65.

12. Ma H, Pederson T, Solomon MJ. The nucleolus stress response is coupled to an ATR-Chk1 - mediated G2 arrest. 2013;

13. Kumar A, Mazzanti M, Mistrik M, Kosar M, Beznoussenko G V., Mironov AA, et al. ATR mediates a checkpoint at the nuclear envelope in response to mechanical stress. Cell. 2014;158(3):633-46.

14. De Klein A, Muijtjens M, Van Os R, Verhoeven Y, Smit B, Carr AM, et al. Targeted disruption of the cell-cycle checkpoint gene ATR leads to early embryonic lethality in mice. Curr Biol. 2000;10(8):479-82.

15. Brown EJ, Baltimore D. ATR disruption leads to chromosomal fragmentation and early embryonic lethality. 2000; (626):397-402.

16. Pan Y, Ren KH, He HW, Shao RG. Knockdown of Chk1 sensitizes human colon carcinoma HCT116 cells in a p53dependent manner to lidamycin through abrogation of a G2/M checkpoint and induction of apoptosis. Cancer Biol Ther. 2009;8(16).

17. Ando K, Kernan JL, Liu PH, Sanda T, Logette E, Tschopp J, et al. Article PIDD Death-Domain Phosphorylation by ATM Controls Prodeath versus Prosurvival PIDDosome Signaling. Mol Cell [Internet]. 2012;47(5):681-93. Available from: 
http://dx.doi.org/10.1016/j.molcel.2012.06.024

18. Ando K, Parsons MJ, Shah RB, Charendoff Cl, Paris SL, Liu PH, et al. NPM1 directs PIDDosome-dependent caspase-2 activation in the nucleolus. 1810;216(6):1795-810.

19. Chen S, Maya-Mendoza A, Zeng K, Tang CW, Sims PFG, Loric J, et al. Interaction with checkpoint kinase 1 modulates the recruitment of nucleophosmin to chromatin. J Proteome Res. 2009;8(10):4693-704.

20. Okuwaki M, Matsumoto K, Tsujimoto M, Y KN. Function of nucleophosmin / B23 , a nucleolar acidic protein , as a histone chaperone. 2001;506:272-6.

21. Maggi LB, Kuchenruether M, Dadey DYA, Schwope RM, Grisendi S, Townsend RR, et al. Nucleophosmin Serves as a Rate-Limiting Nuclear Export Chaperone for the Mammalian Ribosome \. 2008;28(23):7050-65.

22. Amin MA, Matsunaga S, Uchiyama S, Fukui K. Depletion of nucleophosmin leads to distortion of nucleolar and nuclear structures in HeLa cells. 2008;351:345-51.

23. Herrera JE, Savkur R, Olson MOJ. The ribonuclease activity of nucleolar protein B23. 1995;23(19):3974-9.

24. Swaminathan V, Kishore AH, Febitha KK, Kundu TK. Human Histone Chaperone Nucleophosmin Enhances AcetylationDependent Chromatin Transcription †. 2005;25(17):7534-45.

25. Grisendi S, Bernardi R, Rossi M, Cheng K, Khandker L, Manova K, et al. Role of nucleophosmin in embryonic development and tumorigenesis. Nature. 2005;437(7055):147-53.

26. Kozakai Y, Kamada R, Furuta J, Kiyota Y, Chuman Y. PPM1D controls nucleolar formation by up-regulating phosphorylation of nucleophosmin. Nat Publ Gr [Internet]. 2016;(April):1-11. Available from:

http://dx.doi.org/10.1038/srep33272

27. Lin CY, Tan BC, Liu H, Shih C, Chien K, Lin C, et al. Dephosphorylation of Nucleophosmin by PP1 $\otimes$ Facilitates pRB Binding and Consequent E2F1-dependent DNA Repair. 2010;21:4409-17.

28. Sidi S, Sanda T, Kennedy RD, Hagen AT, Jette CA, Hoffmans R, et al. Chk1 Suppresses a Caspase-2 Apoptotic Response to DNA Damage that Bypasses. 2008;2:864-77.

29. Antoine Tinel and Jürg Tschopp. The PIDDosome , a Protein Complex Implicated in Activation of Caspase-2 in Response to Genotoxic Stress: Source : Science, New Series, Vol . 304 , No . 5672 (May 7, 2004 ), pp . 843-846 Published by : Americ. 2016;304(5672):843-6.

30. Baliga BC, Read SH, Kumar S. The biochemical mechanism of caspase-2 activation. Cell Death Differ. 2004;11(11):1234-41.

31. Boatright KM, Renatus M, Scott FL, Sperandio S, Shin H, Pedersen IM, et al. A unified model for apical caspase activation. Mol Cell. 2003;11(2):529-41.

32. Chao TJ, Hao Z. In vitro reconstitution of the interactions in the PIDDosome. 2010;1444-52.

33. Green DR. Caspase-2: the orphan caspase. 2011;19(1):51-7. Available from: http://dx.doi.org/10.1038/cdd.2011.157

34. Park HH, Logette E, Raunser S, Cuenin S, Walz T. Death Domain Assembly Mechanism Revealed by Crystal Structure of the Oligomeric PIDDosome Core Complex. 2007;533-46.

35. Salvesen GS, Dixit VM. Caspase activation: The induced-proximity model. Proc Natl Acad Sci [Internet]. 1999;96(20):10964-7. Available from: http://www.pnas.org/cgi/doi/10.1073/pnas.96.20.10964

36. Troy CM, Ribe EM(2008) Caspase-2: vestigial remnant or master regulator? Sci Signal 1:pe42. doi:10.1126/scisignal.138pe42.

37. Sladky V, Schuler F, Fava LL, Villunger A. The resurrection of the PIDDosome - emerging roles in the DNA-damage response and centrosome surveillance. 2017;53:3779-87.

38. Ho LH, Taylor R, Dorstyn L, Cakouros D, Bouillet P, Kumar S. A tumor suppressor function for caspase-2. Proc Natl Acad Sci. 2009;106(13):5336-41. 
39. Lassus P. Erratum: Requirement for caspase-2 in stress-induced apoptosis before mitochondrial permeabilization (Science (August 23, 2003 (1352)). Science (80- ) [Internet]. 2004;306(5702):1683. Available from:

https://www.scopus.com/inward/record.uri?eid=2-s2.0-

10044224487\&partnerID=40\&md5=b7955072bfc7cb1c4970a7a537e48bf1

40. Robertson JD, Enoksson M, Suomela M, Zhivotovsky B, Orrenius S. Caspase-2 acts upstream of mitochondria to promote cytochrome c release during etoposide-induced apoptosis. J Biol Chem. 2002;277(33):29803-9.

41. Myers K, Gagou ME, Zuazua-villar P, Rodriguez R, Meuth M. ATR and Chk1 Suppress a Caspase-3 - Dependent Apoptotic Response Following DNA Replication Stress. 2009;5(1).

42. Mordes DA, Glick GG, Zhao R, Cortez D. TopBP1 activates ATR through ATRIP and a PIKK regulatory domain. 2008;1478-89.

43. Kumagai A, Lee J, Yoo HY, Dunphy WG. TopBP1 Activates the ATR-ATRIP Complex. 2006;943-55.

44. Bock FJ, Peintner L, Tanzer M, Manzl C, Villunger A. P53-induced protein with a death domain (PIDD): Master of puppets. Oncogene. 2012;31(45):4733-9.

45. Cuenin S, Tinel A, Janssens S, Tschopp J. p53-induced protein with a death domain (PIDD) isoforms differentially activate nuclear factor-kappaB and caspase-2 in response to genotoxic stress. Oncogene. 2008;27(3):387-96.

46. Pick R, Badura S, Bösser S, Zörnig M. Upon intracellular processing, the C-terminal death domain-containing fragment of the p53-inducible PIDD/LRDD protein translocates to the nucleoli and interacts with nucleolin. Biochem Biophys Res Commun. 2006;349(4):1329-38.

47. Huang L, Han D, Yang X, Qin B, Ji G, Yu L. PIDD4, a novel PIDD isoform without the LRR domain, can independently induce cell apoptosis in cytoplasm. Biochem Biophys Res Commun [Internet]. 2011;407(1):86-91. Available from: http://dx.doi.org/10.1016/j.bbrc.2011.02.114

48. Bouchier-Hayes L, Oberst A, McStay GP, Connell S, Tait SWG, Dillon CP, et al. Characterization of Cytoplasmic Caspase2 Activation by Induced Proximity. Mol Cell [Internet]. 2009;35(6):830-40. Available from: http://dx.doi.org/10.1016/j.molcel.2009.07.023

49. Bouchier-Hayes L, Sidi S. The nucleolus: A new home for the PIDDosome. Cell Cycle [Internet]. 2017;16(17):1562-3. Available from: https://www.tandfonline.com/doi/full/10.1080/15384101.2017.1355179

50. Rastogi P, Naseem S, Varma N, Varma S. Immunohistochemical Detection of NPM1 Mutation in Acute Myeloid Leukemia and its Association With Cup-like Nuclear Morphology of Blasts. 2016;24(4):261-7.

51. Balusu R, Fiskus W, Rao R, Chong DG, Nalluri S, Mudunuru U, et al. Targeting levels or oligomerization of nucleophosmin 1 induces differentiation and loss of survival of human AML cells with mutant NPM1. Blood. 2011;118(11):3096-106.

52. Leong SM, Tan BX, Bte Ahmad B, Yan T, Chee LY, Ang ST, et al. Mutant nucleophosmin deregulates cell death and myeloid differentiation through excessive caspase-6 and -8 inhibition. Blood [Internet]. 2010;116(17):3286-96. Available from: http://www.ncbi.nlm.nih.gov/entrez/query.fcgi? cmd=Retrieve\&db=PubMed\&dopt=Citation\&list_uids=20606168\%5Cnhttp://www.ncbi.nlm.nih.gov/pubmed/20606168

53. Bolli N, Payne EM, Grabher C, Lee JS, Johnston AB, Falini B, et al. Expression of the cytoplasmic NPM1 mutant (NPMc+) causes the expansion of hematopoietic cells in zebrafish. Blood. 2010;115(16):3329-40.

54. Burrows AE, Elledge SJ. How ATR turns on: TopBP1 goes on ATRIP with ATR. 2008;(617):1416-21.

55. Mccoy F, Eckard L, Nutt LK. A Sensor for DNA Damage-Induced Cell Death or Survival? Mol Cell [Internet]. 2012;47(5):667-8. Available from: http://dx.doi.org/10.1016/j.molcel.2012.08.019

56. Bhattacharya $D$, Hiregange $D$ et al. ATR kinase regulates its attenuation via PPM1D phosphatase recruitment to chromatin during recovery from DNA replication stress signalling. 2018 Biosci.j; http://dx.doi.org/10.1007/s12038018-9736 
57. Mahajan S, Raina K, Verma S, Rao BJ. International Journal of Biochemistry and Cell Biology Human RAD52 protein regulates homologous recombination and checkpoint function in BRCA2 de fi cient cells. Int J Biochem Cell Biol [Internet]. 2019;107(December 2018):128-39. Available from: https://doi.org/10.1016/j.biocel.2018.12.013

58. Wang W, Budhu A, Forgues M, Wang XW. Temporal and spatial control of nucleophosmin by the Ran-Crm1 complex in centrosome duplication. Nat Cell Biol. 2005;7(8):823-30.

59. XU Y, Anderson DE, Ye Y. The HECT domain ubiquitin ligase HUWE1 targets unassembled soluble proteins for degradation. Cell Discov [Internet]. 2016;2:1-16. Available from: http://dx.doi.org/10.1038/celldisc.2016.40.

\section{Figures}

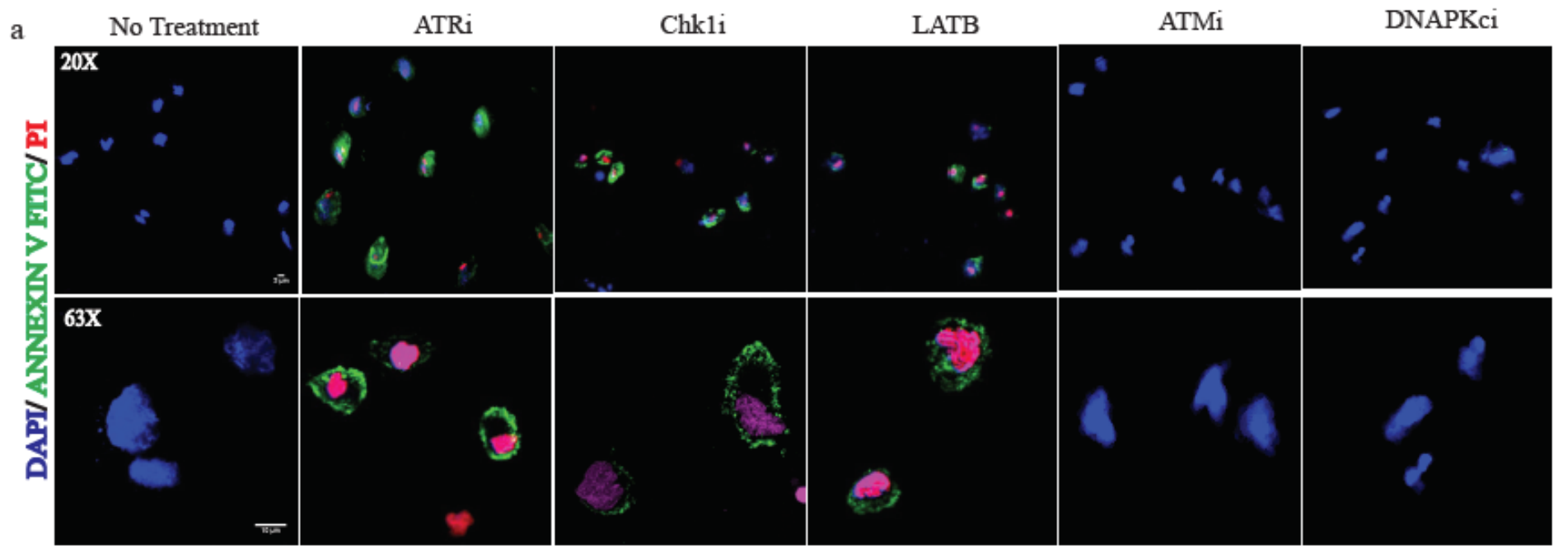

$\mathrm{b}$

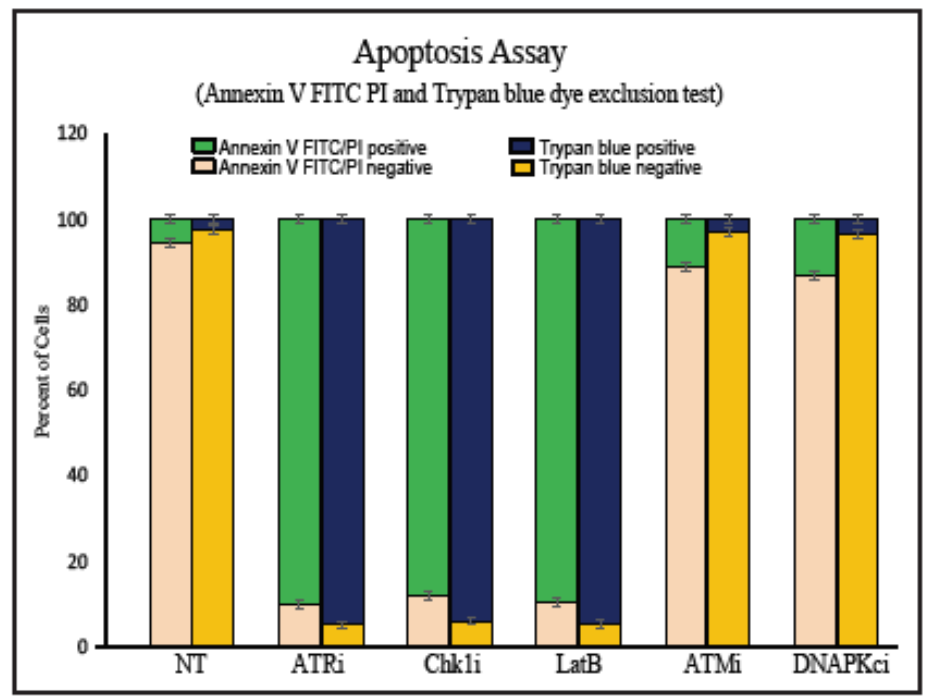

c

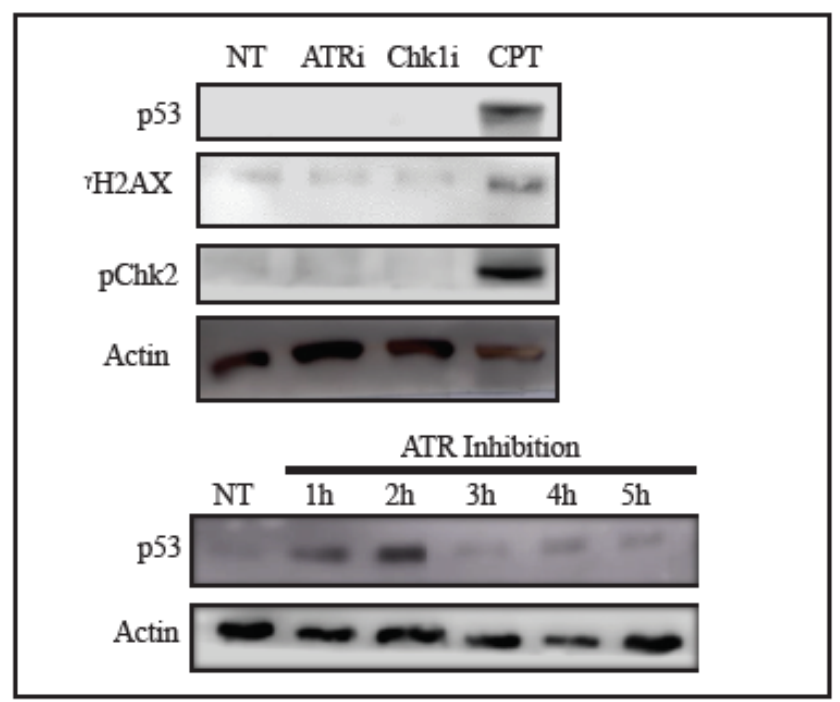

\section{Figure 1}

Prolonged ATR kinase inhibition causes cell death in normal cells: Asynchronous culture of NHDFs were treated with specific chemical inhibitor (5h) for ATRi, LatB, Chk1i, ATMi and DNAPKci, followed by cell death assays (Annexin V FITC PI assay and Trypan blue dye exclusion test). (a) Representative images of Annexin V FITC PI staining of the inhibitor treated samples (upper panel at 20X magnification; lower panel at 63X magnification). (b) Quantitation of samples described in panel-A (NT: "No Treatment") N=3,n=100. Error bars represent the s.e.m. (c) HEK293 cells were treated with specific chemical inhibitor (5h) for ATRi, Chk1 $\mathrm{i}$ and Cisplatin, and immunoblotted for $\mathrm{YH} 2 \mathrm{AX}, \mathrm{p} 53$ and pChk2 using actin as a loading control. Cells from specific time-points of ATRi inhibition were immunoblotted for p53. 


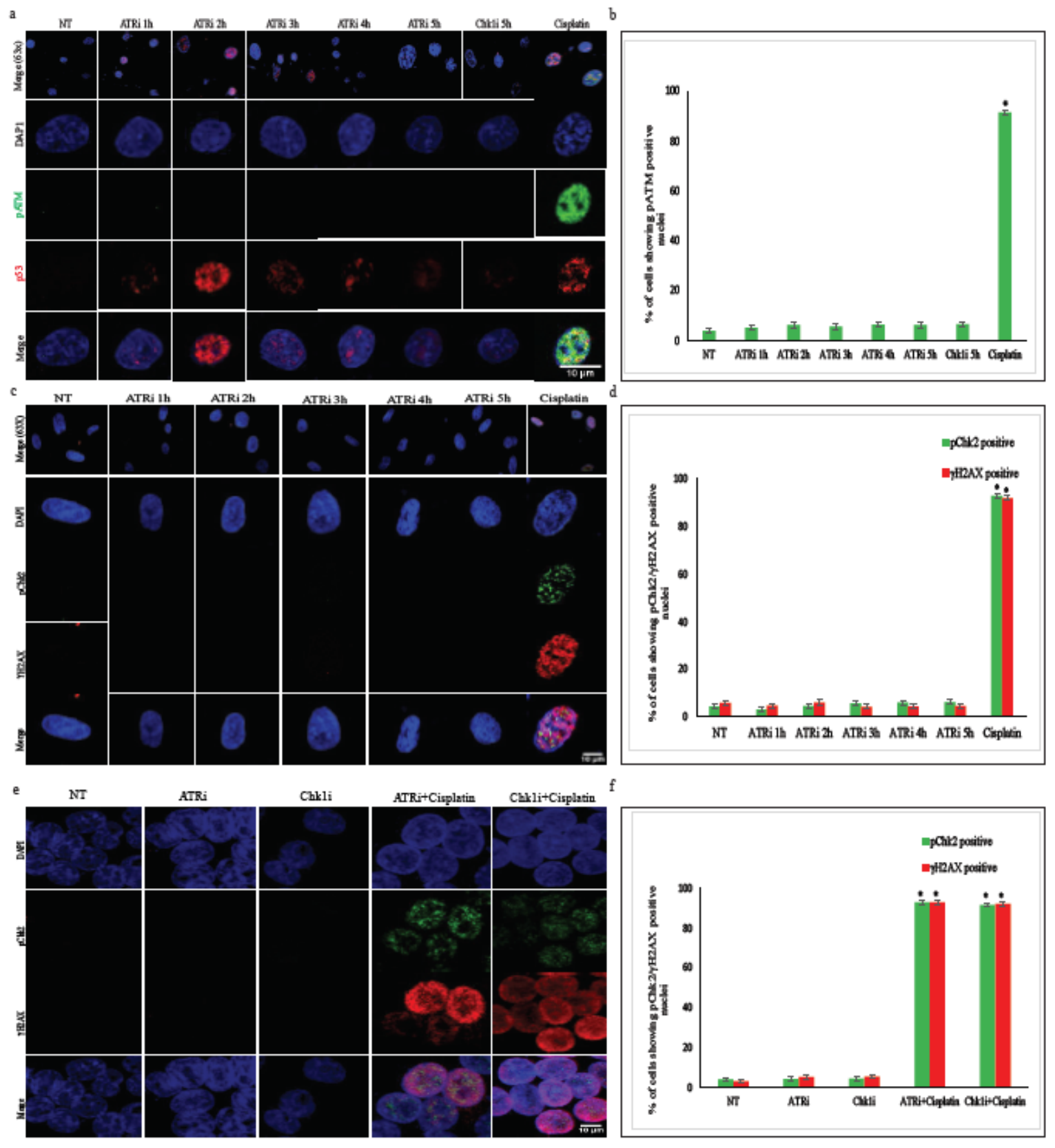

Figure 2

ATR kinase inhibition neither hampers ATM kinase activity nor leads to its activation: (a) NHDFs from specific time-points of ATRi inhibition were fixed, nuclei counterstained with DAPI, or stained for pATM or p53. Chk1i and Cisplatin treated (5h) samples were similarly processed. Nuclei Images were captured in ZIESS 510 microscope at 100X magnification. (b) Quantitation of percentage of pATM positive nuclei in the samples. At least 100 nuclei/sample were analysed and scored for pATM positivity and was averaged for three independent biological replicates. (c) NHDFs from specific time-points of ATRi inhibition were fixed, nuclei counterstained with DAPI, or stained for $\mathrm{yH} 2 \mathrm{AX}$ and pChk2. Cisplatin treated (5h) samples were similarly processed. Nuclei Images were captured in ZIESS 510 microscope at 100X magnification. (d) Quantitation of percentage of $\mathrm{YH} 2 \mathrm{AX} / \mathrm{pChk} 2$ positive nuclei in the samples. At least 100 nuclei/sample were analysed and scored for $\mathrm{YH} 2 \mathrm{AX} / \mathrm{pChk} 2$ positivity and was averaged for three independent biological replicates. (e) HEK293 from specific timepoints of ATRi, Chk1i, ATRi + Cisplatin and Chk1i + Cisplatin treatment were fixed, nuclei counterstained with DAPI, or stained for $\mathrm{YH} 2 \mathrm{AX}$ and pChk2. Nuclei Images were captured in ZIESS 510 microscope at 100X magnification. (f) 
Quantitation of percentage of $\mathrm{yH} 2 \mathrm{AX} / \mathrm{pChk} 2$ positive nuclei in the samples. At least 100 nuclei/sample were analysed and scored for $\mathrm{YH} 2 \mathrm{AX} / \mathrm{pChk} 2$ positivity and was averaged for three independent biological replicates.
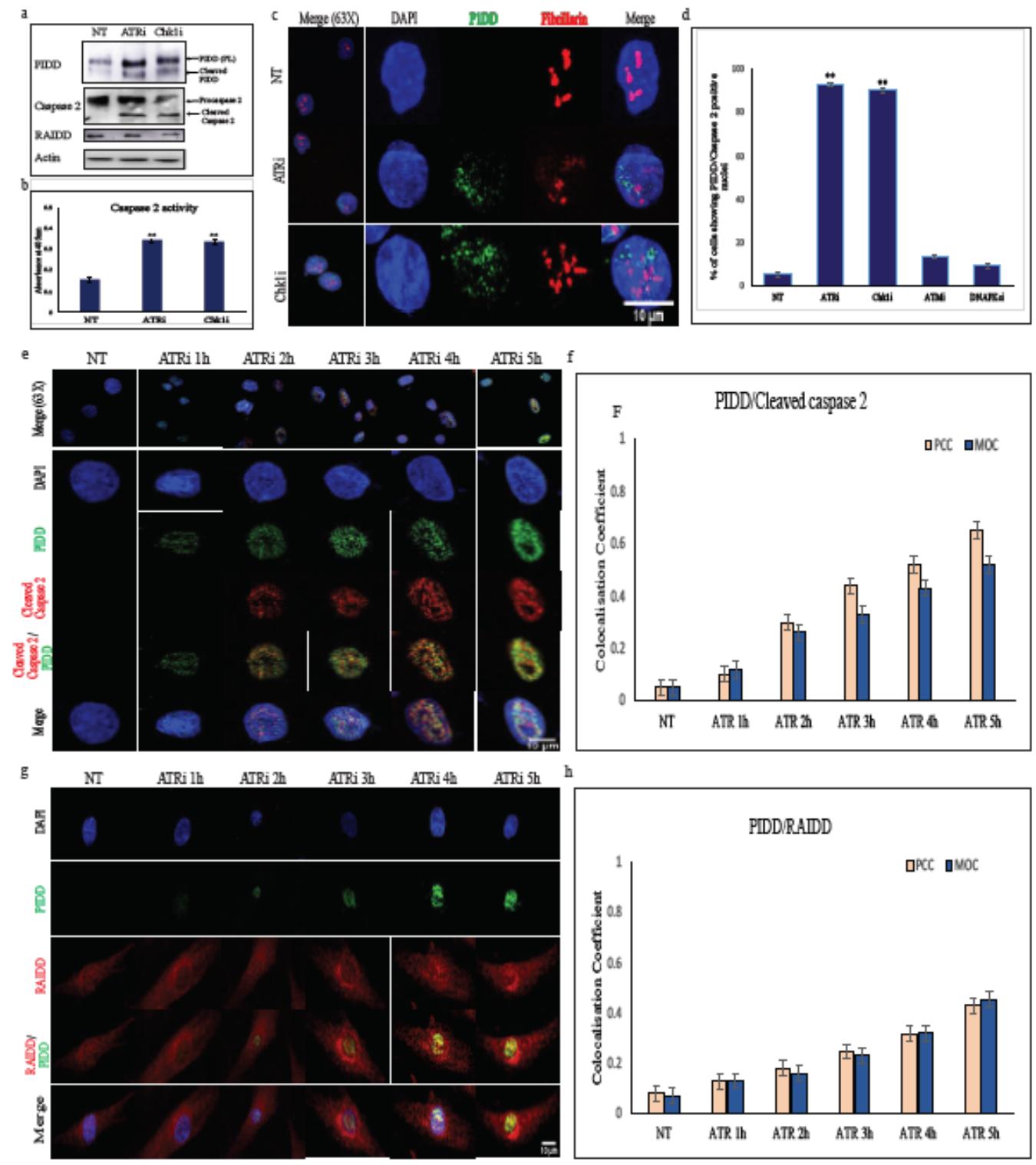

Figure 3

Prolonged inhibition of ATR kinase activity leads to the activation of PIDDosome signalling: (a) ATRi and Chk1i (5h treated) HEK293 samples were immunoblotted for PIDD, Caspase 2 or RAIDD using actin as a loading control. (b) Caspase 2 activity measured by absorbance at $405 \mathrm{~nm}$ in HEK293 cells on ATR kinase and Chk1 kinase inhibition using Caspase 2 assay kit. (c) ATRi, Chk1i (5h treated) NHDF samples were either counterstained with DAPI, stained for PIDD or fibrillarin. (d) Quantitation of percentage of PIDD/Caspase 2 positive nuclei in the samples. At least 100 nuclei/sample were analysed and scored for PIDD/Caspase 2 positivity and was averaged for three independent biological replicates. (e) ATRi (of varying time-points i.e.,1 hour to 5 hours) NHDFs were either counterstained with DAPI, stained for PIDD or cleaved caspase 2. (f) Colocalisation coefficient of PIDD and cleaved caspase 2 on images from panel c. (g) ATRi (of varying timepoints i.e., 1 hour to 5 hours) NHDFs were either counterstained with DAPI, stained for PIDD or RAIDD. (h) Colocalisation coefficient of PIDD and RAIDD on images from panel $d$. 

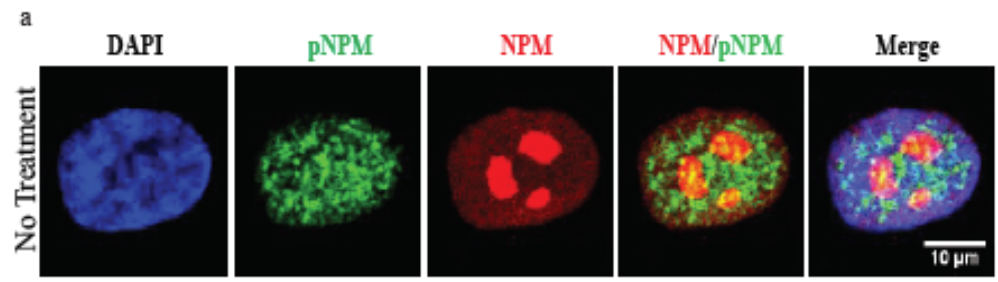

b

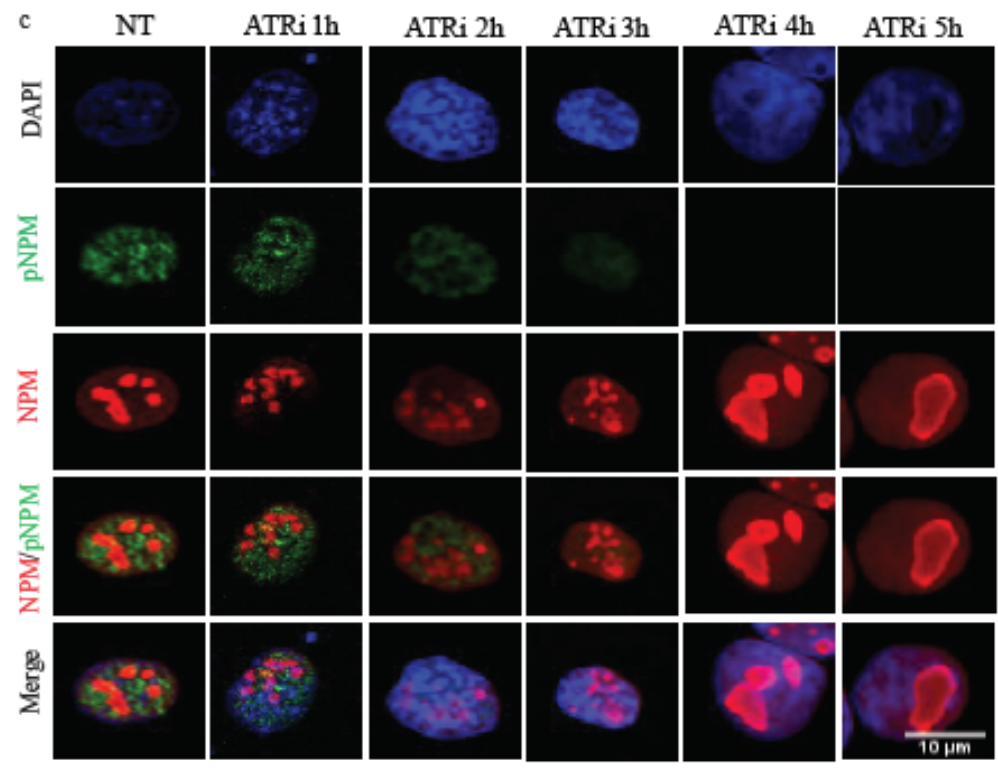

d
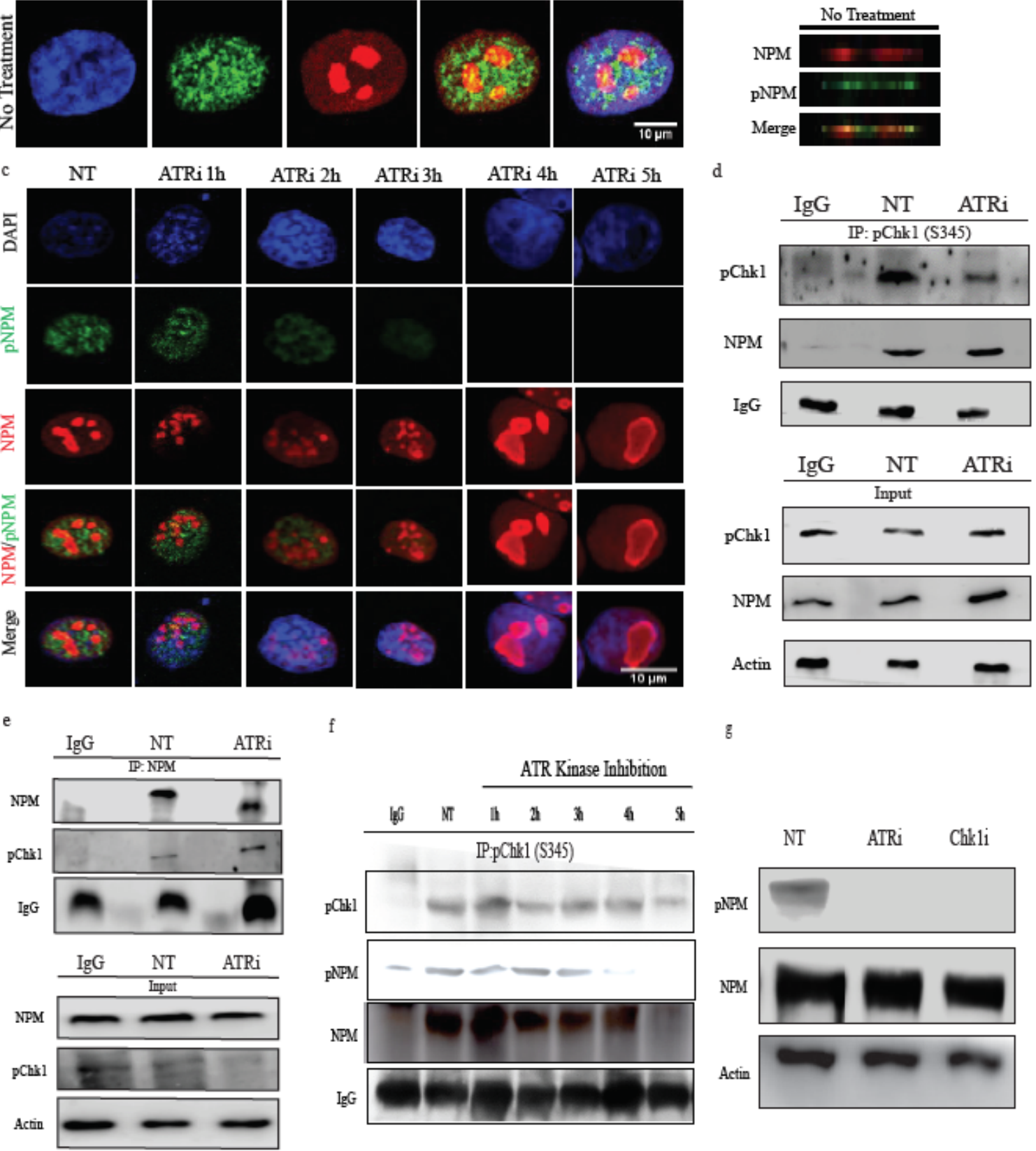

f

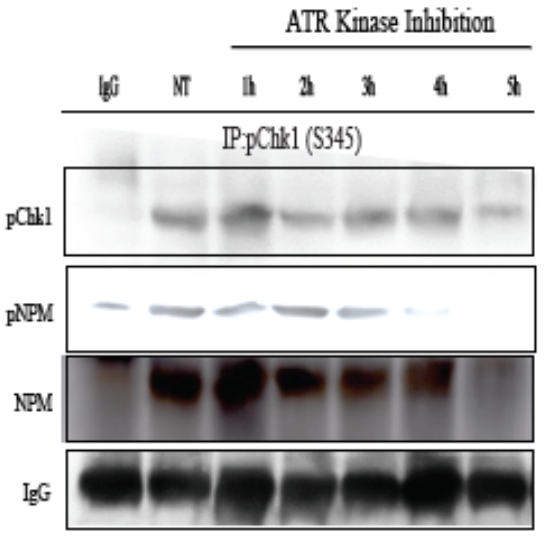

g
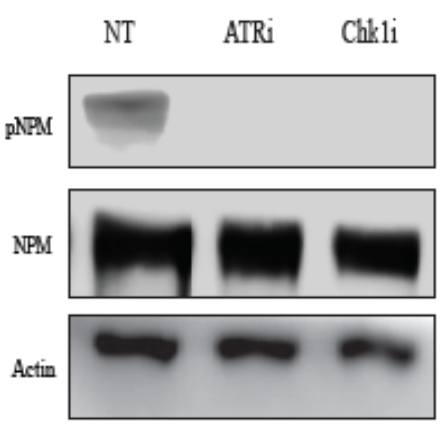

\section{Figure 4}

Prolonged inhibition of ATR kinase activity leads to the loss of pChk1 interaction with NPM resulting in the drop of cellular pNPM level: (a) Untreated NHDFs were counterstained with DAPI, or stained for NPM or pNPM (ZIESS 510 microscope at 100X magnification). (b) Orthogonal view of the representative images. (c) ATRi (of varying time-points i.e.,1 hour to 5 hours) NHDFs were either counterstained with DAPI, stained for NPM or pNPM. Nuclei Images were captured in ZIESS 510 microscope at 100X magnification. (d-e) HEK293 cells [untreated, or ATRi (5h)] were harvested and processed for either pChk1 IP (panel d) or NPM IP (panel e), followed by immunoblotting for pChk1, NPM and IgG. Bottom panels: Total cell lysates were immunoblotted for pChk1, NPM and actin for IP-inputs. (f) ATRi (of varying time-points i.e., 1 hour to 5 hours) HEK293 samples were harvested and processed for pChk1 IP, followed by immunoblotting for pChk1, NPM, pNPM and IgG. (g) Total cell extracts from HEK293 cells [No Treatment (NT), ATRi (5h) or Chk1i (5h)] were immunoblotted for pNPM, NPM using actin as a loading control. $\mathrm{N}=3$. 

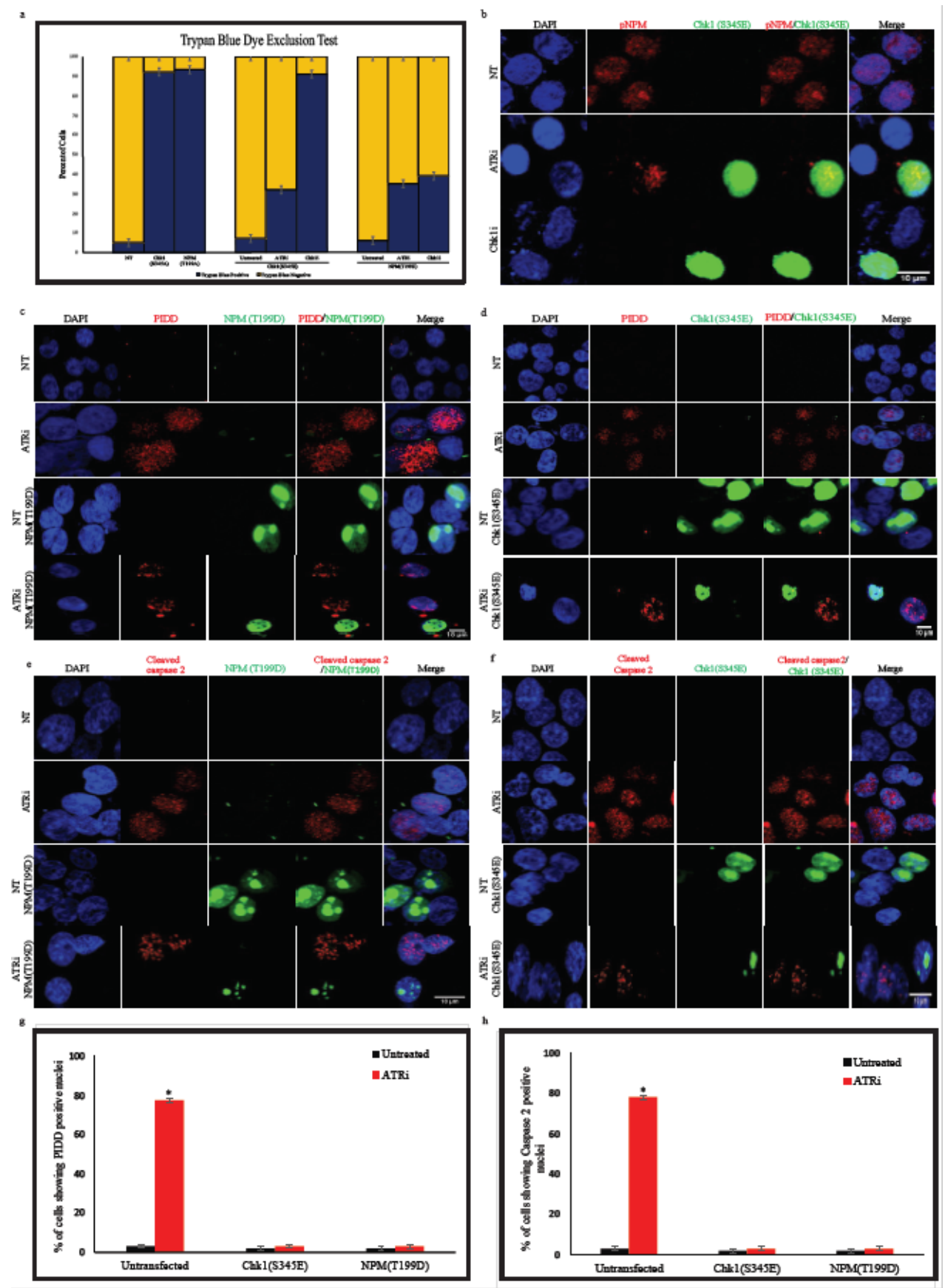

Figure 5

NPM and Chk1 phosphorylation are essential for cell survival: (a) HEK293 cells transfected with phosphomimic mutant [Chk1(S345E) or NPM(T199D)] or phosphodead mutant [Chk1 (S345A) or NPM (T199A)] were treated with ATRi or Chk1i (5h) followed by Trypan blue dye exclusion test and quantification of the response. First panel: Control and phophodead mutant cells without inhibitor treatment; Second panel: Chk1-phosphomimic mutant (NT, ATRi \& Chk1i); Third panel: NPMphosphomimic mutant (NT, ATRi \& Chk1i) $N=3, n=100$. Error bars represent the s.e.m. (b) Phosphomimic mutant of Chk1(S345E) expressing cells [NT, ATRi (5h) or Chk1i (5h)] were counterstained with DAPI or immunostained for pNPM or flag-tagged Chk1. (c) Phosphomimic mutant of NPM (T199D) expressing cells [NT or ATRi (5h)] were counterstained with DAPI or immunostained for PIDD or GFP tagged NPM. (d) Phosphomimic mutant of Chk1(S345E) expressing cells [NT or ATRi (5h)] were counterstained with DAPI or immunostained for PIDD or flag-tagged Chk1. (e) Phosphomimic mutant of NPM (T199D) expressing cells [NT or ATRi (5h)] were counterstained with DAPI or immunostained for cleaved caspase 2 or GFP-tagged NPM. (f) Phosphomimic mutant of Chk1(S345E) expressing cells [NT or ATRi (5h)] were counterstained with 
DAPI or immunostained for cleaved caspase 2 or flag-tagged Chk1. All images were captured in ZIESS 510 microscope at 63X magnification. (g) Quantitation of percentage of cells PIDD positive nuclei in the samples. At least 100 nuclei/sample were analysed and scored for PIDD positivity and was averaged for three independent biological replicates. (h)

Quantitation of percentage of cells Caspase 2 positive nuclei in the samples. At least 100 nuclei/sample were analysed and scored for Caspase 2 positivity and was averaged for three independent biological replicates.

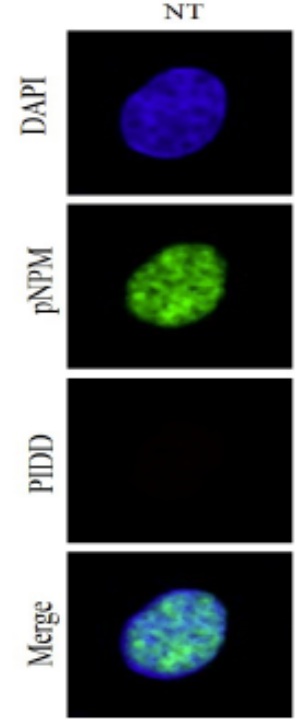

c
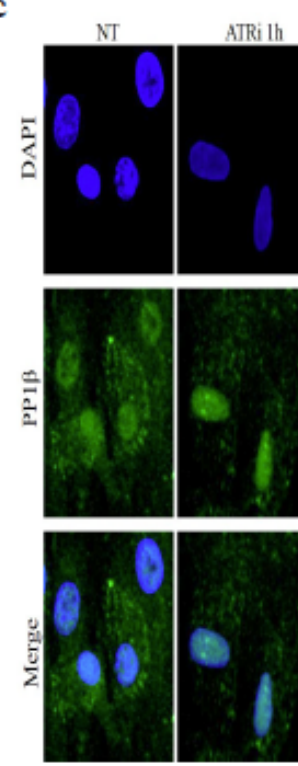

PPM1Di ih
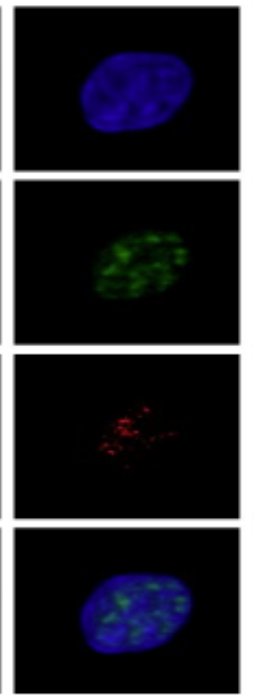

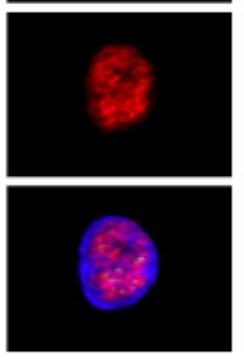

PPM1Di $3 \mathrm{~h}$
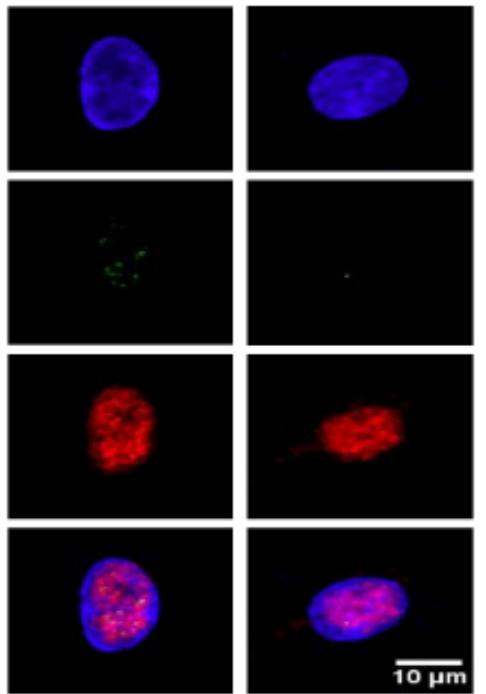

$\overline{10 \mu \mathrm{m}}$ b

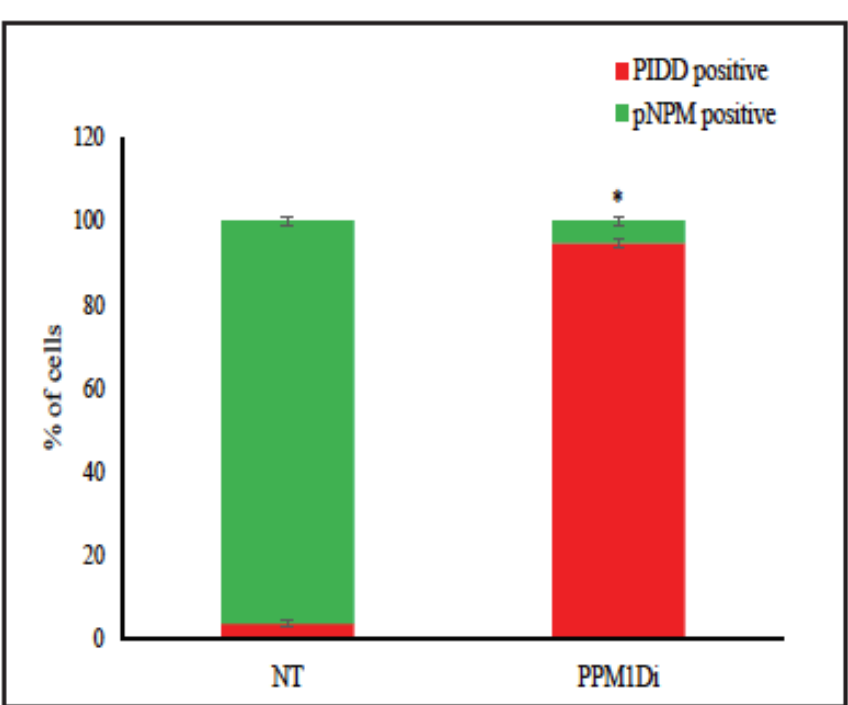

d

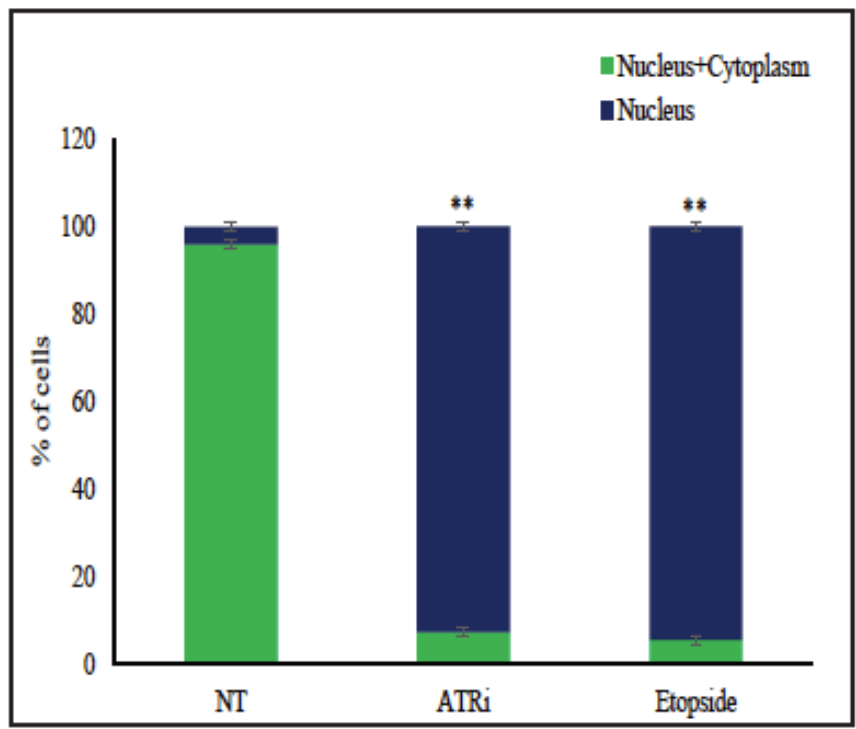

Figure 6

Phosphatase regulation of PIDDosome signalling: (a) NHDF cells were treated with specific chemical inhibitor (3h) for PPM1D (PPM1Di) and immunostained for PIDD and pNPM. Nuclei counterstained with DAPI, or stained for pNPM or PIDD.

(b) Quantitation of percentage of cells pNPM/PIDD positive nuclei in the samples. At least 100 nuclei/sample were analysed and scored for pNPM/PIDD positivity and was averaged for three independent biological replicates. (c) NHDFs from specific time-points of ATRi inhibition were fixed, nuclei counterstained with DAPI, or stained for PP1 $\beta$. Etopside treated (3h) samples were used as positive control. Nuclei Images were captured in ZIESS 510 microscope at 100X magnification. (d) Quantitation of percentage of cells showing PP1 $\beta$ localisation change in the samples. At least 100 nuclei/sample were analysed and scored for PP1 $\beta$ localisation change and was averaged for three independent biological replicates. 
ATR Kinase active

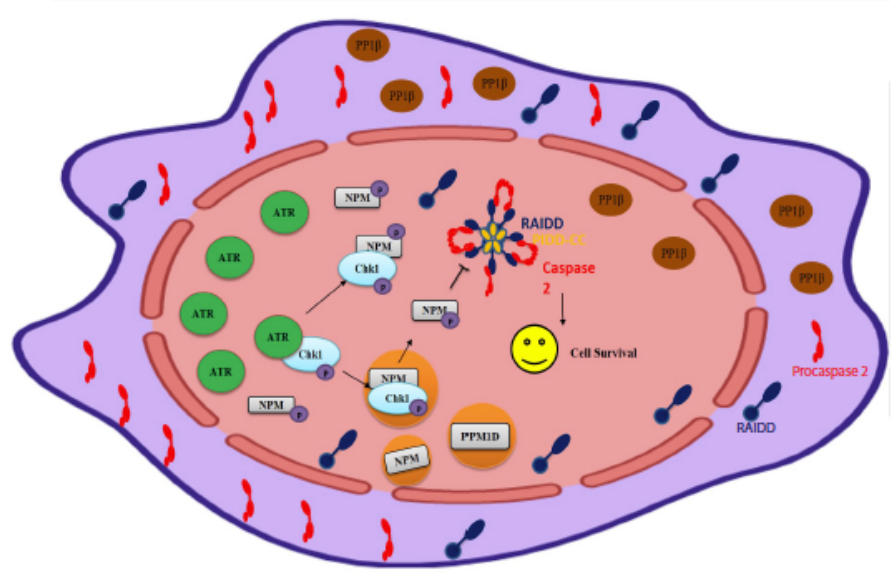

ATR Kinase inactive

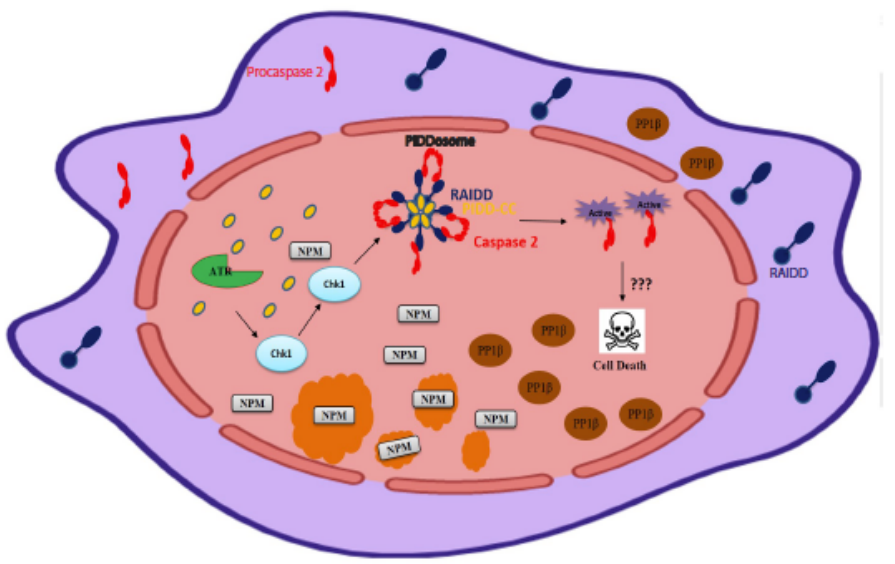

Figure 7

Model for prosurvival role of ATR kinase: In a normal cell, active ATR kinase leads to the maintenance of certain threshold level of pChk1 which interacts with NPM and phosphorylates the same. pNPM (nucleoplasm/chromatin) homeostasis leads to sustained negative regulation on PIDDosome assembly, thereby preventing caspase 2 activation (Left panel). Any condition that leads to the attenuation of cellular ATR kinase activity imbalances the ATR-pChk1-pNPM-PPM1D axis and changes the localisation of PP1 $\beta$ phosphatase that in turn leads to the depletion of nuclear pNPM levels, undoing the intrinsic negative regulation imposed by ATR on PIDDosome assembly. Activation of PIDDosome assembly in such conditions triggers caspase 2 mediated cell death in the cells (Right panel).

\section{Supplementary Files}

This is a list of supplementary files associated with this preprint. Click to download.

- AdditionalFile3.pdf

- AdditionalFile1.pdf

- AdditionalFile2.pdf

- AdditionalTable2.pdf

- AdditionalTable1.pdf 